\title{
The Relationship Between Students' Learning Styles and Academic Performance: Final Year Accounting Students
}

\author{
Noor Saatila Mohd Isa ${ }^{a}$, Norliana Omar ${ }^{\mathrm{a}}$, Farah Husna Mohd Fatzela, \\ Zulkifli Mohd Ghazalib, Norazmi Anas ${ }^{\mathrm{c}}$
}

\author{
${ }^{a}$ Faculty of Accountancy, Universiti Teknologi MARA, Perak Branch, \\ Tapah Campus, Perak, Malaysia \\ ${ }^{b}$ Faculty of Computer Science and Mathematics, Universiti Teknologi MARA, Perak Branch, \\ Tapah Campus, Perak, Malaysia \\ ${ }^{c}$ Academic of Contemporary Islamic Studies, Universiti Teknologi MARA, Perak Branch, \\ Tapah Campus, Tapah, Perak, Malaysia \\ *e-mail: noors464@uitm.edu.my
}

Received: 02 September 2020; Accepted: 18 November 2020; Published: 01 January 2021

To cite this article (APA): Anas, N., Mohd Isa, N. S., Omar, N., Mohd Fatzel, F. H., \& Mohd Ghazali, Z. (2021). The relationship between students' learning styles and academic performance: Final year accounting students. EDUCATUM Journal of Social Sciences, 7(1), 1-9. https://doi.org/10.37134/ejoss.vol7.1.1.2021

To link to this article: https://doi.org/10.37134/ejoss.vol7.1.1.2021

\begin{abstract}
Accounting students at tertiary education basically prefer different types of learning styles. This study investigated the impact of the relationship among the learning style preferences of undergraduate accounting students, awareness of learning styles and their academic achievements. Participants of the study consisted of all the final year accounting students in UiTM Tapah. The results indicated that the students prefer kinesthetic learning modality, and for the rest of the modalities students found that they are generally well-balanced. The study found that there were significant awareness of learning styles among students particularly for the kinesthetic type of students. However, based on the test conducted, there was no significant correlation between the academic achievement and the learning style preferences of the students. There was also no significant relationship between learning styles and awareness of the learning styles. Hence, types of learnings styles do not contribute directly to the accounting students' academic performance.
\end{abstract}

Keywords: learning styles, academic performance, awareness of learning styles

\section{INTRODUCTION}

Over the years, there has been numerous studies conducted to investigate the effects of learning styles in education. Generally, learning style is defined as the method in which learners perceive, process, interpret, organize, and think about information. Learners normally have their preferred ways of identifying, organizing, and holding information efficiently and effectively (Chou \& Wang, 2000). McAllister (2010) claimed that by creating a pleasant learning environment and practising teaching methods that closely match the students' preferred learning styles, educators will be able to assist students to achieve better academic performance.

Learning style is a combination of cognitive, emotional, and physiological factors that are influenced by environmental factors. There are numerous models of learning styles and a variety of measurement instruments that can assess them including the validated VARK questionnaire created by Fleming (2006). VARK is an acronym for Visual, Aural, Read/Write, and Kinesthetic sensory modalities. The learning style can be divided into two categories. Unimodal learners have only one dominant learning preference and can be classified into four styles, V, A, R/W, and K. The visual-aural-read/writekinesthetic (VARK) questionnaire is a simple, freely available, easy to administer tool that encourages students to describe their behavior in a manner they can accept and identify with. Some examples of 
the VARK learning style preferences (LSPs) are: Visual (looking at and making pictures, animations, graphs, tables, etc.); aural (listening to and participating in speeches, discussions, and question answer sessions); read/write (reading and writing text associated with the textbook, class notes, laboratory reports, etc.) and Kinesthetic (engaging in physical experiences and manipulating objects, for example in laboratories). The "multimodal learners" have a balanced set of learning preferences, including the bimodal, trimodal and quamodal.

Accounting subjects have always been negative perceived by the students. Basically, accounting course comprises theoretical and application parts that require students' ability and capability to successfully comprehend the topics. Therefore, students need to apply the appropriate learning styles that will help them in the theoretical part of the accounting course and the applications of the accounting principles (Adler, Whiting \& Wynn-Williams, 2004). Without suitable learning styles, students might feel that accounting is one of the difficult subjects to achieve higher grade (Elias, 2005). Therefore, educators have experienced significant challenges in getting students' attention and interest. Exploring their learning styles can change their negative perception that ultimately will affect their academic performance. By knowing their preference, educators might be able to match the learning activities and students' preferred style to actively engage students in the learning process.

Currently, there is a limited number of research done to investigate the learning styles of undergraduate accounting students. Hence, in response to this issue, the purpose of this study is to explore the relationship between learning style and academic performance among final year accounting students who are enrolled in two accounting programs: diploma in accounting program, and diploma in accounting information systems program. By understanding this relationship, the present study provides useful information to develop an effective instructional strategy, promote academic performance and enhance accounting education. Additionally, the objective of this study is to identify the awareness among the accounting students of different learning styles. Students can acquire more information in a shorter period if they become aware of their learning style preferences.

\section{LITERATURE REVIEW}

There are a number of inventories developed in order to determine students' different learning preferences in an attempt to accommodate them with a more complementing teaching strategy which improves the students' academic performance (Arthurs, 2007). Among those widely used are Mumford's Learning Style Questionnaire, Kolb's Learning Style Indicator, Dunn, and Dunn Learning Style Model and VARK. For the purpose of this study, VARK questionnaire, which is based on interaction and response to learning environment of students, is adopted. VARK questionnaire is chosen as it is easy to use and serve as a tool that provides information on ways to maximize the students' learning by suggesting the strategy that best suit their preference. Moreover, there were only a few studies conducted by using this learning style inventory, specifically among accounting students in Malaysian public universities. Using VARK questionnaire to identify students' preferred learning styles is the key approach which can be used to increase the quality of teaching and learning process.

VARK learning style inventory is developed by Fleming (2006) and it has been commonly used ever since. It classifies students into four different learning preferences, namely visual, aural/auditory, $\mathrm{read} / \mathrm{write}$ and Kinesthetic. Hence, the name of the inventory, is taken from the prefix of those modals itself. Othman and Amiruddin (2010) in their study explained that visual mode students have the tendency to learn by describing pictures, charts, mind maps and diagrams, whereas students with aural mode are likely to capture information through lectures, tutorials, discussions and dialogues. As for reading type of students, they can accept and interpret printed information such as quotations, dictionaries, list, and other materials. Finally, Kinesthetic mode is the situation in which the students accept learning better from experience, simulation and practice using sensory like touch and feel. There are also students who embrace the combination of any two, three or all four modals mentioned, and this is called multimodal. These varieties in learning styles are believed to have an influence on the academic performance of higher education students (Abidin, Rezaee, Abdullah, \& Singh, 2011; Yeung, Read, \& Schmid, 2012).

In a study conducted by Kim, Gilbert, and Ristig (2015) among the general surgery residents at a university hospital-based program in America, it was found that the residents with the dominant read 
learning style achieved the highest scores in their in-training examination whereas the aural dominant learners had the lowest scores in the same assessment. In another study involving dental students in Iran, almost all of the respondents preferred a mixed learning method. The results found that there was a significant difference in the final exam scores between students with and without visual mode learning preference, with the latter scored significantly lower than the former (Nasiri, Gharekhani, \& Ghasempour, 2016). On the contrary, Bracci, Tallaki, and Castellini (2019) in their empirical study with undergraduate and postgraduate accounting students have proved that visualization seems to be less relevant in improving the presentation of accounting knowledge, thus concurrently would not be able to maximize students' full potential. In a blended learning environment, things are surprisingly a bit conventional. Students with a read/write inclination seem to significantly outperform the others, with Kinesthetic learners stand the lowest (Vasileva-Stojanovska, Malinovski, Vasileva, Jovevski, \& Trajkovik, 2015). Nuzhat, Salem, Hamdan, and Ashour (2013) in their study among medical students in Saudi Arabia found that students with multimodal learning preference achieved comparatively better results than their unimodal counterparts in the same course. Other than that, Stevens (2013) has investigated the learning styles effects on few variables among undergraduate business statistics students. He found that the preferences significantly affected the variables which included academic success.

However, that is not the case in the study by Gohar and Sadeghi (2015) where they found no significant difference in the academic performance of Iranian students with different learning styles. Similar results among Pakistani students were also found by Razzak, Shaikh, and Siddiqui (2019) in which different learning preferences did not affect their current grade point average (GPA). They claimed that this could be due to other determinants like lack of awareness of the learning styles as well as the way learning was assessed that distort the relation of the two variables. Rogowsky, Calhoun, and Tallal (2015) in their study have demonstrated that providing learning based on preferred learning styles did not improve learning, slashing the famous meshing hypothesis which claims that the calibration between learning style and instruction yields optimal outcomes. Kirschner (2017) in his bold and evidence-informed study convinced many that this propaganda and myth on learning styles must stop as it did not at all affect learning outcomes due to several problems. One of them is that the way someone prefers to learn does not always lead to effective and efficient learning. This is supported by Liew, Sidhu, and Barua (2015) as well as Awang, Samad, Faiz, Roddin, and Kankia (2017) as they too found no significant contribution of learning styles towards learning outcomes. Other than those mentioned above, with different settings of classes, be it online or in-class learning, the method brought no difference on academic performance with different learning methods (Cimermanova, 2018).

Studies have demonstrated that students typically bring in their learning style preferences into their learning environment (Nuzhat, Salem, Quadri, \& Al-Hamdan, 2011), which then could lead to the enhancement of their academic performance as a result of the favourable act. This could take place only if they are aware of which learning method that they are good at. Awareness is one of the factors driving an act to be performed. In a study carried out by Bhutkar and Bhutkar (2016), there was an improvement in the academic performance of $51 \%$ of the total respondents after they were made aware of their tendency in learning style and realigned their study strategies. Similarly, Barman, Aziz, and Yusoff (2014) demonstrated a significant increase in the GPAs of a group of nursing students after they attended a workshop that made them discover their individual learning style. Other than that, when students are alert of their own study advantage, plus the appropriate teaching style they get from the educators, their understanding of the course content improves (V, 2011). This is in line with the research findings by Geiser et al. (2000) who performed a study on hundred thirty 8th-grade students in a suburban district in America. They found that students who were taught to study according to their learning style profiles when studying for mathematics test scored significantly higher marks as compared to their batch mates who studied traditionally.

As such, these findings serve as a basis in arriving to the curiosity of whether different learning styles and learning styles awareness would influence the academic performance of accounting students. 


\section{RESEARCH METHODOLOGY}

\section{Sample Selection}

A total of five hundred final year accounting undergraduate students in UiTM Tapah took part in this study. Simple random sampling was done in order to select a sample for this study. Among the five hundred questionnaires that were handed out, two hundred and fifty eight questionnaires were completed, and 2 questionnaires were discarded as incomplete, because there was missing information: 2 respondents had left some questions unanswered. Hence, the final response rate was $52 \%$. However, the sample size of two hundred fifty eight respondents met the minimum requirement of sample size for five hundred population size. According to Krejcie and Morgan (1970), the minimum sample size for five hundred population size is two hundred and seventeen sample size.

\section{Data Collection}

Online questionnaire was used as an instrument in collecting the data. The questionnaire was adopted from VARK questionnaire. The self-perceived learning style preference was identified along with demographic and academic performance data. Participants were asked to describe their learning style(s) by choosing from the following options: 1) visual (learning from graphs, charts, flow diagrams, and demos); 2) aural (learning from speech, lectures, and discussions); 3) reading/writing (learning from reading and writing); and 4) kinesthetic (learning from performing an activity, touch, hearing, smell, taste, and sight). The latest English version 8.01 of the VARK questionnaire in a printed form was used. Validity and reliability of the VARK questionnaire have been recently established. It consisted of 16 questions with 4 options for each. Each option correlates to a sensory modality preference. Hence, the modality that received the highest marks was the preferred sensory modality. Since students were free to select more than one option, multiple modalities of varying combinations could be obtained. The questions describe situations of common occurrence in daily life, thereby relating to an individual's learning experience. Students were instructed to choose the answer that best explained their preference and circle the letter(s) next to it. They could choose more than one option or leave blank any question that they felt was not applicable to them. In term of student awareness of learning styles, respondents were asked 5 questions rated on a 5 Likert scale ranging from (1) Strongly Disagree; (2) Disagree; (3) Neutral; (4) Agree; (5) Strongly Agree. Respondents have to indicate their level of agreement or disagreement on items provided.

\section{Data Analysis}

Data were analyzed using SPSS and reported as the percentage of respondents in each learning preference category. The descriptive statistics which are frequency, percentage, graph and cross tabulation table were used to summarize the data. To answer the main objective, the chi-square test of association was used to examine the relationship between students' CGPA and learning preferences. The chi-square test is used because the dependent and independent variables are categorical variable with more than two groups.

\section{RESULTS AND DISCUSSION}

Initially, students or the respondents were asked to complete questionnaires that have 4 different types of learning styles as previously discussed. In addition, in this study the researchers include another category which is multimodal: for this modality, respondents do not have a standout mode with one preference score well above other scores of the four modalities. Table 1 shows that most of the students are classified under Kinesthetic learning style which amounted to one hundred sixty one respondents 
(62.4\%) of the total respondents of two humdred fifty eight graduating accounting students. In other words, Kinesthetic learning style is a style of learning by engaging, moving, undergoing, and experimenting with the task or work given.

Table 1: Frequency of respondents based on learning styles

\begin{tabular}{lcc}
\hline \multicolumn{1}{c}{ Learning Style } & Frequency & Percentage \\
\hline Visual & 28 & 10.9 \\
Aural & 37 & 14.3 \\
Read \& Write & 10 & 3.9 \\
Kinesthetic & 161 & 62.4 \\
Multimodal & 22 & 8.5 \\
\hline
\end{tabular}

This result may be due to the personality traits or behaviour of the students themselves which was the reason behind their choice to pursue their study in accounting course. As accounting students, they must undergo or fully engage into the work task given by their lecturers for them to understand the accounting treatments. The distribution of respondents' frequencies seems to be fairly distributed amongst the other 4 modalities. Visual modality shows twenty eight respondents, and this is not quite different with multimodal and aural modality that involved thirty seven respondents. Read \& write shows the lowest number of respondents with this learning styles and this result is contrary to the one tabled out by Vasileva-Stojanovska, Malinovski, Vasileva, Jovevski and Trajkovik (2015).

Table 2 shows the number of respondents according to their range of CGPA which is the measurement for academic performance. One hundred thirty six respondents have CGPA 3.50 and above $(52.7 \%)$. Only one student scored below than CGPA 2.00. So, the study can conclude that respondents are amongst the high achievers in academic performance. The CGPA was included because the researcher wanted to see the relationship between learning styles and academic performance.

Both Table 1 and Table 2 show a consistency pattern with Table 3. To discuss further, Table 3 shows that respondents with Kinesthetics domain scored the majority cluster of respondents who have CGPA above 3.50. Multimodal, Visual and Aural domains show the frequency of 13, 14 and 15 respectively. Read and write modality scores the lowest frequency of CGPA above 3.50.

Table 2: Frequencies of respondents based on CGPA

\begin{tabular}{lcc}
\multicolumn{1}{c}{ CGPA } & Frequency & Percentage \\
\hline Less than 2.00 & 1 & 4 \\
$2.00-2.49$ & 6 & 2.3 \\
$2.50-2.99$ & 28 & 10.9 \\
$3.00-3.49$ & 87 & 33.7 \\
3.50 and above & 136 & 52.7 \\
\hline
\end{tabular}

This research then continues to test the relationship between these 2 groups of learning styles with CGPA using chi-square test. It was found that there was no significant relationship between learning styles and academic performance (Table 4: Chi-Square tests Learning Styles VS CGPA). Our result is consistent with Gohar and Sadeghi (2015) who found the same results. The researcher assumed that since the subjects are amongst the high achievers, learning styles do not really contribute directly to their academic performance. There must have been other attributes that helped them to achieve such range of CGPA, such as their own awareness, personality, environment, or many other factors.

Table 3: LSs * CGPA Crosstabulation

\begin{tabular}{|c|c|c|c|c|c|}
\hline & \multicolumn{5}{|c|}{ CGPA } \\
\hline & & Less than 3.00 & $3.00-3.49$ & 3.50 and above & Total \\
\hline \multirow[t]{5}{*}{$\overline{\mathrm{LSs}}$} & Visual & 4 & 10 & 14 & 28 \\
\hline & Aural & 8 & 14 & 15 & 37 \\
\hline & Read \& Write & 2 & 2 & 6 & 10 \\
\hline & Kinesthetic & 18 & 55 & 88 & 161 \\
\hline & Multimodal & 3 & 6 & 13 & 22 \\
\hline Total & & 35 & 87 & 136 & 258 \\
\hline
\end{tabular}


Relationship Between Students' Learning Styles and Academic Performance: Final Year Accounting Students

Table 4: Chi-Square Tests Learning Styles VS CGPA

\begin{tabular}{lccc}
\hline & Value & df & Asymp. Sig. (2-sided) \\
\hline Pearson Chi-Square & $2.129^{\mathrm{a}}$ & 2 & .345 \\
Likelihood Ratio & 2.079 & 2 & .354 \\
Linear-by-Linear Association & 1.570 & 1 & .210 \\
N of Valid Cases & 258 & & \\
\hline
\end{tabular}

Therefore, we have extended this study by looking into the awareness of the respondents about their learning styles after they identified the category of learnings styles that they belong to. Moreover, the researchers wanted to know whether this awareness contributes to their academic performance. Another reason to include awareness questions in the questionnaire was because the researchers wanted to know whether potential respondents are aware of their own learning styles that could have help them in fully utilising their capabilities. Table 5 shows that majority of the respondents (123 respondents) is 'somewhat familiar' with their own learning styles. Only 5 of the respondents were not familiar at all with their own learning styles.

Table 5: Awareness of learning styles 1

\begin{tabular}{|c|c|c|c|c|c|}
\hline \multicolumn{2}{|l|}{ Items } & $\begin{array}{l}\text { Not at all } \\
\text { familiar }\end{array}$ & $\begin{array}{l}\text { Not too } \\
\text { familiar }\end{array}$ & $\begin{array}{l}\text { Somewhat } \\
\text { familiar }\end{array}$ & $\begin{array}{c}\text { Very } \\
\text { familiar }\end{array}$ \\
\hline \multirow{2}{*}{$\begin{array}{l}\text { Are you aware that different learning } \\
\text { styles exist? (B1) }\end{array}$} & No. & 3 & 28 & 115 & 112 \\
\hline & $\%$ & 1.2 & 10.9 & 44.6 & 43.4 \\
\hline \multirow{2}{*}{$\begin{array}{l}\text { Are you familiar with your own } \\
\text { learning styles? (B2) }\end{array}$} & No. & 5 & 49 & 123 & 81 \\
\hline & $\%$ & 1.9 & 19 & 47.7 & 31.4 \\
\hline \multirow{2}{*}{$\begin{array}{l}\text { Are you familiar with learning } \\
\text { strategies of different types of learners } \\
\text { in your group? (B3) }\end{array}$} & No. & 8 & 91 & 121 & 38 \\
\hline & $\%$ & 3.1 & 35.3 & 46.9 & 14.7 \\
\hline
\end{tabular}

Table 6: Awareness of Learning Styles 2

\begin{tabular}{llccccc}
\hline \multicolumn{1}{c}{ Items } & & $\mathbf{( 1 )}$ & $\mathbf{( 2 )}$ & $\mathbf{( 3 )}$ & $\mathbf{( 4 )}$ & $\mathbf{( 5 )}$ \\
\hline I actively exchanged my learning styles (LSs) with my & $\mathbf{N o .}$ & 19 & 40 & 121 & 71 & 7 \\
group members. (B4) & $\mathbf{( \% )}$ & 7.4 & 15.5 & 46.9 & 27.5 & 2.7 \\
I was able to incorporate the LSs of other in my group & $\mathbf{N o .}$ & 3 & 29 & 120 & 96 & 10 \\
into my own LS (B5) & $\mathbf{( \% )}$ & 1.2 & 11.2 & 46.5 & 37.2 & 3.9 \\
Discussing about LSs is an effective method of & $\mathbf{N o .}$ & 1 & 8 & 74 & $\mathbf{1 2 5}$ & $\mathbf{5 0}$ \\
enhancing my learning (B6) & $\mathbf{( \% )}$ & 0.4 & 3.1 & 28.7 & $\mathbf{4 8 . 4}$ & $\mathbf{1 9 . 4}$ \\
I was able to identify which was the best combination of & $\mathbf{N o .}$ & 2 & 17 & 78 & $\mathbf{1 1 5}$ & $\mathbf{4 6}$ \\
LSs for me (B7) & $\mathbf{( \% )}$ & 0.8 & 6.6 & 30.2 & $\mathbf{4 4 . 6}$ & $\mathbf{1 7 . 8}$ \\
Combining new LSs helped me in performing better in & $\mathbf{N o .}$ & 0 & 14 & 84 & 106 & 54 \\
the examination (B8) & $\mathbf{( \% )}$ & 0 & 5.4 & 32.6 & 41.1 & 20.9 \\
\hline
\end{tabular}

(1) Strongly Disagree; (2) Disagree; (3) Neutral; (4) Agree; (5) Strongly Agree

Table 7: Learning Styles VS B6 \& B7

\begin{tabular}{llccccc}
\hline & & & B6 & & \\
& & Disagree & Neutral & Agree & Strongly Agree & Total \\
\hline \multirow{4}{*}{ LS } & Visual & 1 & 11 & 11 & 5 & 28 \\
Aural & 1 & 8 & 20 & 8 & 37 \\
Read \& Write & 0 & 1 & 8 & 1 & 10 \\
& Kinesthetic & 7 & 44 & $\mathbf{7 8}$ & $\mathbf{3 2}$ & 161 \\
& Multimodal & 0 & 10 & 8 & 4 & 22 \\
$\quad$ Total & 9 & 74 & 125 & 50 & 258 \\
\hline
\end{tabular}




\begin{tabular}{llccccc}
\hline & & Disagree & Neutral & Agree & Strongly Agree & Total \\
\hline \multirow{4}{*}{ LS } & Visual & 4 & 8 & 9 & 7 & 28 \\
& Aural & 1 & 10 & 18 & 8 & 37 \\
Read \& Write & 1 & 1 & 5 & 3 & 10 \\
& Kinesthetic & 11 & 48 & $\mathbf{7 5}$ & $\mathbf{2 7}$ & 161 \\
& Multimodal & 2 & 11 & 8 & 1 & 22 \\
$\quad$ Total & 19 & 78 & 115 & 46 & 258 \\
\hline
\end{tabular}

Table 6 shows that one hundred seventy five of the respondents agreed on the fact that discussing learning styles is an effective method of enhancing their learning process $(67.8 \%)$ and one hundred sixty one respondents agreed on the fact that they are able to identify the best combination of learning styles modalities that suits them (62.4\%). Therefore, lecturers should blend all the modalities during the teaching-learning process. Among the respondents, 110 (B6) and 102 (B7) of them fall under Kinesthetic domain, while 9 (B6) and 19 (B7) disagree with the statements as shown further in Table 7. The relationship between learning styles categories and awareness of learning styles has been further tested using chi-square test to find the significance of this relationship.

Table 8: Chi-Square Tests Learning Styles VS Awareness

\begin{tabular}{lccc}
\hline & LS VS B6 & & \\
\hline Pearson Chi-Square & $1.234^{\mathrm{a}}$ & $\mathrm{df}$ & Asymp. Sig. (2-sided) \\
Likelihood Ratio & 1.305 & 3 & .745 \\
Linear-by-Linear Association & .001 & 1 & .728 \\
N of Valid Cases & 258 & & .972 \\
& LS VS B7 & & \\
& Value & df & Asymp. Sig. (2-sided) \\
\hline Pearson Chi-Square & $.907^{\mathrm{a}}$ & 4 & .924 \\
Likelihood Ratio & .902 & 4 & .924 \\
Linear-by-Linear Association & .019 & 1 & .889 \\
N of Valid Cases & 258 & & \\
\hline
\end{tabular}

a. 2 cells (20.0\%) have expected count less than 5. The minimum expected count is .75.

However, we also found no significant relationship between learning styles and awareness of those learning styles as shown in Table 8. Therefore, it is affirmative that the types of learnings styles do not contribute directly to the students' academic performance. The result is consistent with previous study conducted locally by Awang, Samad, Faiz, Roddin and Kankia (2017) which stated that learning styles exhibited no significant difference by students towards the academic achievement in Malaysian Polytechnic. This is further supported by Cimermanová (2018) who has found that the results of a twoway analysis of variance (ANOVA) of her study showed no significant findings which indicate that the learning styles and form of teaching have no effect on students' academic achievement.

\section{CONCLUSION}

In conclusion, our study was an attempt to describe the learning styles of undergraduate accounting students in our institution. Previous studies claimed that a better understanding of learning styles could bring a favourable result to both educators and students. For educators, understanding learning styles is crucial especially in developing teaching techniques and curriculum design. According to the results, there was no significant difference between learning style and students' academic achievement. Students' academic achievement is like their individual learning styles. It means that the types of learnings styles do not contribute directly to the students' academic performance. This might be due to different students may use different ways to learn in their academic field. Other contributing factors 
need to be considered instead of learning styles alone to improve students' performance. Therefore, this study shows that each learning style has its own strengths and limitations.

There are several limitations in this study. Firstly, the data were collected among final year accounting students in UiTM Tapah for the sample. The selection of this sample may not be an accurate representation of all accounting students. Therefore, future research can be improved by enlarging the sample size to a wider scope. This can be done by including accounting students from other institutions in the data collection process as it would strengthen the representation of the population. Secondly, this study only covers academic performance of students such as learning styles and learning styles awareness. Further research can be expanded to also examine the effects of teaching reform strategies based on the learning style preference of the final year accounting students from this study. The diversification of teaching strategies probably can suit a wider variety of learning styles, thereby helping to minimise mismatches between learning and teaching styles. Lastly, the data gathered in this research were totally based on face-to-face class session. Since teaching and learning process is undergoing rapid changes which involve the shift from physical classroom to online platform, it is interesting to compare the data from both environments in order to provide an insight whether learning platform brings any differences in determining the students' learning styles as well as influencing their academic performance.

\section{REFERENCES}

Abidin, M. J. Z., Rezaee, A. A., Abdullah, H. N., \& Singh, K. K. B. (2011). Learning Styles and Overall Academic Achievement in a Specific Educational System. International Journal of Humanities and Social Science, $1(10)$.

Arthurs, J. B. (2007). A juggling act in the classroom: Managing different learning styles. Teaching and Learning in Nursing, 2(1), 2-7. doi:https://doi.org/10.1016/j.teln.2006.10.002

Awang, H., Samad, N. A., Faiz, N. S. M., Roddin, R., \& Kankia, J. D. (2017). Relationship between the Learning Styles Preferences and Academic Achievement. International Research and Innovation Summit.

Barman, A., Aziz, R. A., \& Yusoff, Y. M. (2014). Learning Style Awareness and Academic Performance of Students. South East Asian Journal of Medical Education, 8(1).

Bhutkar, M. V., \& Bhutkar, P. M. (2016). Effect of Awareness of Learning Styles and Modifications in Study Modalities on Academic Performance in First MBBS Students. National Journal of Basic Medical Sciences, 7(1).

Bracci, E., Tallaki, M., \& Castellini, M. (2019). Learning Preferences in Accounting Education: A Focus on the Role of Visualization. Meditari Accountancy Research, 28(2).

Cimermanova, I. (2018). The Effect of Learning Styles on Academic Achievement in Different Forms of Teaching. International Journal of Instruction, 11(3).

Fleming, N. D. (2006). V.A.R.K Visual, Aural/Auditory, Read/Write, Kinesthetic. New Zealand: Bonwell Green Mountain Falls.

Geiser, W. F., Dunn, R., Deckinger, E. L., Denig, S., Sklar, R. I., Beasley, M., \& Nelson, B. (2000). Effects of Learning-Style Awareness and Responsive Study Strategies on Achievement, Incidence of Study, and Attitudes of Suburban Eighth-Grade Students. National Forum of Special Education Journal, $9 E$.

Gohar, M. J., \& Sadeghi, N. (2015). The Impact of Learning Style Preferences on Foreign Language Achievement: A Case Study of Iranian EFL Students. Procedia - Social and Behavioral Sciences, 171, 754-764. doi:https://doi.org/10.1016/j.sbspro.2015.01.188

Kim, R. H., Gilbert, T., \& Ristig, K. (2015). The Effect of Surgical Resident Learning Style Preferences on American Board of Surgery In-Training Examination Scores. Journal of Surgical Education, 72(4), 726731. doi:https://doi.org/10.1016/j.jsurg.2014.12.009

Kirschner, P. A. (2017). Stop propagating the learning styles myth. Computers \& Education, 106, 166-171. doi:10.1016/j.compedu.2016.12.006

Liew, S.-C., Sidhu, J., \& Barua, A. (2015). The Relationship between Learning Preferences (Styles and Approaches) and Learning Outcomes among Pre-clinical Undergraduate Medical Students. BMC Medical Education.

Nasiri, Z., Gharekhani, S., \& Ghasempour, M. (2016). Relationship between Learning Style and Academic Status of Babol Dental Students. Electronic Physician, 8(5), 2340-2345. doi:10.19082/2340 
Nuzhat, A., Salem, R. O., Hamdan, N. A., \& Ashour, N. (2013). Gender differences in learning styles and academic performance of medical students in Saudi Arabia. Medical Teacher, 35, S78-S82. doi:10.3109/0142159X.2013.765545

Nuzhat, A., Salem, R. O., Quadri, M. S. A., \& Al-Hamdan, N. (2011). Learning style preferences of medical students: a single-institute experience from Saudi Arabia. International Journal of Medical Education, 2, 70-73. doi:10.5116/ijme.4e36.d31c

Othman, N., \& Amiruddin, M. H. (2010). Different Perspectives of Learning Styles from VARK Model. Procedia - Social and Behavioral Sciences, 7, 652-660. doi:https://doi.org/10.1016/j.sbspro.2010.10.088

Razzak, F., Shaikh, S., \& Siddiqui, A. (2019). EXPLORING EFFECTS OF LEARNING STYLES ON LEARNING OUTCOMES. New Horizons (1992-4399), 13(1), 13-30. doi:10.2.9270/NH.13.1(19).02

Rogowsky, B. A., Calhoun, B. M., \& Tallal, P. (2015). Matching Learning Style to Instructional Method: Effects on Comprehension. Journal of Educational Psychology, 107(1), 64-78. doi:10.1037/a0037478

Stevens, D. P. (2013). Assessing the Effects of Learning Style in Business Statistics. International Journal of Innovation and Learning, 13(3).

V, M. (2011). An Analysis of Some Factors Affecting Student Academic Performance in an Introductory Biochemistry Course at the University of the West Indies. The Carribean Teaching Scholar, 1(2).

Vasileva-Stojanovska, T., Malinovski, T., Vasileva, M., Jovevski, D., \& Trajkovik, V. (2015). Impact of satisfaction, personality and learning style on educational outcomes in a blended learning environment. Learning and Individual Differences, 38, 127-135. doi:https://doi.org/10.1016/j.lindif.2015.01.018

Yeung, A., Read, J., \& Schmid, S. (2012). Students' Learning Styles and Academic Performance in First Year Chemistry. Proceedings of the Australian Conference on Science and Mathematics Education, 11. 